\title{
Rathke Cleft Cyst with a Coexisting Gonadotropin Producing Pituitary Adenoma
}

\author{
Chi-Man Yip1, Hui-Hwa Tseng², Shu-Shong Hsu1, Huang-I Hsu1* \\ ${ }^{1}$ Division of Neurosurgery, Department of Surgery, Kaohsiung Veterans General Hospital, Kaohsiung, Taiwan \\ ${ }^{2}$ Department of Pathology, Kaohsiung Veterans General Hospital, Kaohsiung, Taiwan \\ Email: yip chiman@yahoo.com, hhtseng@vghks.gov.tw, sshsu@vghks.gov.tw, McCoyHsu@gmail.com
}

Received 29 April 2015; accepted 7 June 2015; published 10 June 2015

Copyright (C) 2015 by authors and Scientific Research Publishing Inc.

This work is licensed under the Creative Commons Attribution International License (CC BY). http://creativecommons.org/licenses/by/4.0/

(c) () D Open Access

\begin{abstract}
Rathke cleft cyst is thought to arise from incomplete obliteration of the lumen of Rathke pouch. The cells of the anterior pituitary lobe, from which pituitary adenomas develop, are also derived from the cells of Rathke pouch. Although Rathke cleft cyst and pituitary adenoma have a shared ancestry, they rarely occur coincidentally. Rathke cleft cysts have been found incidentally in $11 \%$ $33 \%$ of post-mortem examinations, and were associated with $1.7 \%-2.1 \%$ of the pituitary adenoma cases. These coexisting lesions are difficult to diagnose pre-operatively due to the variable signal intensity and position of the Rathke cleft cysts. Treatment of these lesions involves surgical resection to decrease mass effect and medical management to normalize hormonal imbalances. To our best knowledge, only 42 cases of Rathke cleft cyst with a coexisting pituitary adenoma have been reported in the English or Japanese literatures, but none of the coexisting pituitary adenoma is gonadotropin producing. We would like to report a case of Rathke cleft cyst with a coexisting gonadotropin producing adenoma that was successfully treated by endoscopic endonasal transsphenoidal approach with the removal of the sellar lesion and temporary hormone replacement.
\end{abstract}

\section{Keywords}

Rathke Cleft Cyst, Gonadotropin Producing Pituitary Adenoma, Coexisting Lesions, Endoscopic Endonasal Transsphenoidal Approach

\section{Introduction}

Rathke cleft cyst (RCC), first described by Luschka in 1860 [1] [2], is thought to arise from incomplete obliteration of the lumen of Rathke pouch. This embryonic structure develops as a rostral outpouching of the stomodeum or

\footnotetext{
${ }^{*}$ Corresponding author.
} 
primitive oral cavity during the third or fourth week of gestation. It has an anterior and posterior wall, as well as a central embryonic cleft. The anterior wall of the pouch proliferates to form the anterior lobe of the pituitary gland and the pars tuberalis; the posterior wall becomes the pars intermedia [1]-[5]. The residual lumen of the pouch is reduced to the narrow Rathke cleft, which usually regresses completely. The cells of the anterior pituitary lobe, from which pituitary adenomas develop, are also derived from the cells of Rathke pouch [1]-[3]. Although RCC and pituitary adenoma have a shared ancestry, they rarely occur coincidentally [2] [3] [5] [6]. To our best knowledge, only 42 cases of Rathke cleft cyst with a coexisting pituitary adenoma has been reported in the English or Japanese literatures, but none of the coexisting pituitary adenoma is gonadotropin producing [2] [5] [6]. We would like to present a case of Rathke cleft cyst with a coexisting gonadotropin producing adenoma which probably is the first reported combination.

\section{Case Report}

In December 2013, a 66-year-old man with past medical history of hypertension for five years, Legionella pneumonia with adult respiratory distress syndrome (ARDS) post treatment in June 2013 presented to us with the chief complaint of progressive blurred vision for more than two months. Traced back his past medical history, he was diagnosed to have a sellar lesion in 2007. His magnetic resonance imaging (MRI) at that time showed a cystic lesion measured about $1.7 \mathrm{~cm} \times 1.3 \mathrm{~cm} \times 1.2 \mathrm{~cm}$ in size at the sella and suprasellar region, manifesting hyperintensity both on T1-weighted (T1WI) and T2-weighted (T2WI) images without obvious solid enhancement (Figure 1). This lesion showed mild mass effect on the optic chiasm, however, he hesitated to have surgical treatment. He was on cortisone replacement since the previous admission due to Legionella pneumonia. On admission, his neurological examination was essentially normal except his visual field study showed bitemporal hemianopia. Sellar MRI was repeated which disclosed a cystic mass lesion with some solid enhancement, about $3.2 \mathrm{~cm} \times 2.5 \mathrm{~cm} \times 2 \mathrm{~cm}$ in size located at sella with suprasellar extension, manifesting iso- to hypo-intensity on T1WI and hyperintensity on T2WI images, causing the compression of optic chiasm (Figure 2). Endocrinological data were obtained; his cortisol level was normal (under regular cortisone replacement) but hypothyroidism as well as hypogonadism were shown. The pre-operative tentative diagnosis was Rathke cleft cyst or pituitary macroadenoma with cystic change.

On January 3, 2014, under general anesthesia, he underwent endoscopic endonasal transsphenoidal approach with the removal of the sellar lesion. A zero degree endoscope was introduced into the right side nostril to identify the sphenoid ostium. After the perpendicular plate of ethmoid bone was disarticulated and pushed to the left side, the rostrum of the sphenoid sinus was exposed and drilled to complete the sphenoidotomy. Then the sellar floor was exposed and drilled; the capsule of the lesion was opened, the solid tumor tissue rushed out followed by the outflowing of the mucinous contents (Figure 3). After the removal of the solid and the cystic components of the lesion, a piece of DuraGen was placed in the subdural space to cover the pituitary gland and a piece of thin bone harvested from the resected sella turcica was used to reconstruct the sellar floor followed by spraying tissue glue on the reconstructive materials.

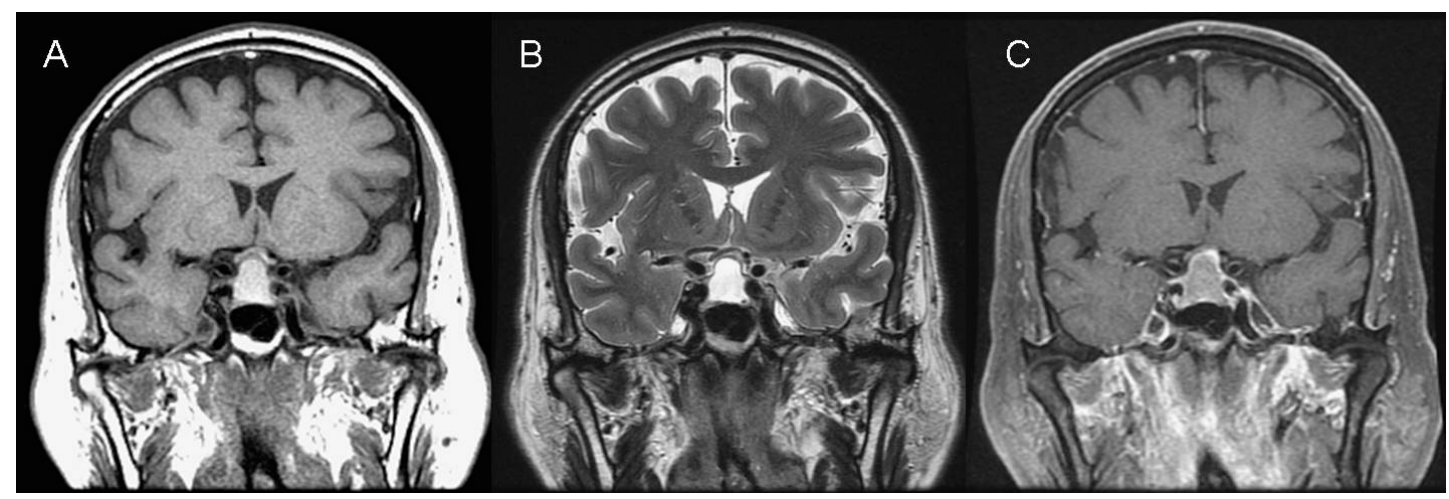

Figure 1. Coronal view of patient's sellar MRI in 2007. (A) T1-weighted images (B) T2-weighted images (C) T1weighted with Gadolinium demonstrating a cystic lesion measured about $1.7 \mathrm{~cm} \times 1.3 \mathrm{~cm} \times 1.2 \mathrm{~cm}$ in size at the sella and suprasellar region, manifesting hyperintensity both on T1-weighted and T2-weighted images without obvious solid enhancement. 


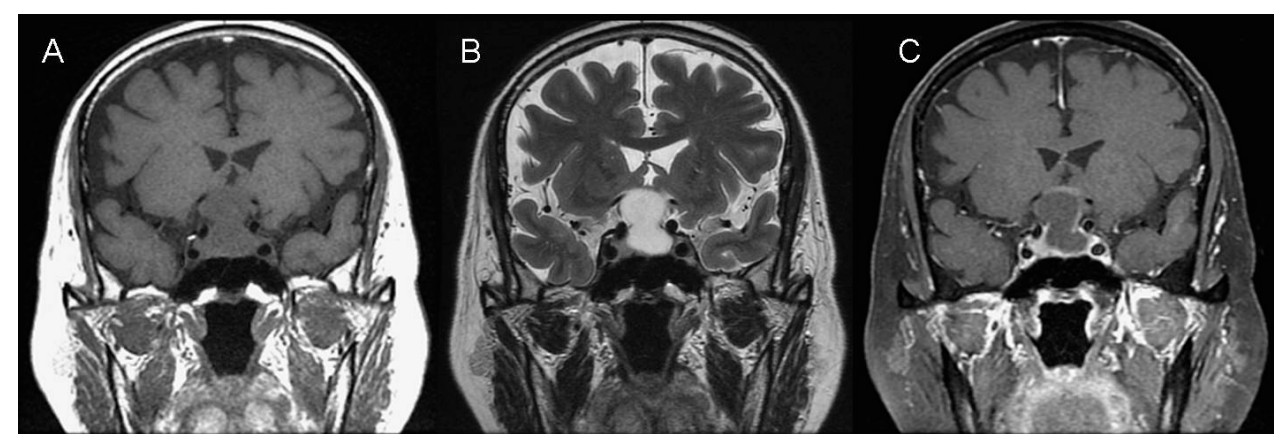

Figure 2. Coronal view of patient's sellar MRI in 2013. (A) T1-weighted images; (B) T2-weighted images; (C) T1-weighted with Gadolinium disclosing a cystic mass lesion about $3.2 \mathrm{~cm} \times 2.5 \mathrm{~cm} \times$ $2 \mathrm{~cm}$ in size located at sella with suprasellar extension, manifesting iso- to hypo-intensity on T1-weighted and hyperintensity on T2-weighted images, with some solid enhancement, causing the compression of optic chiasm.

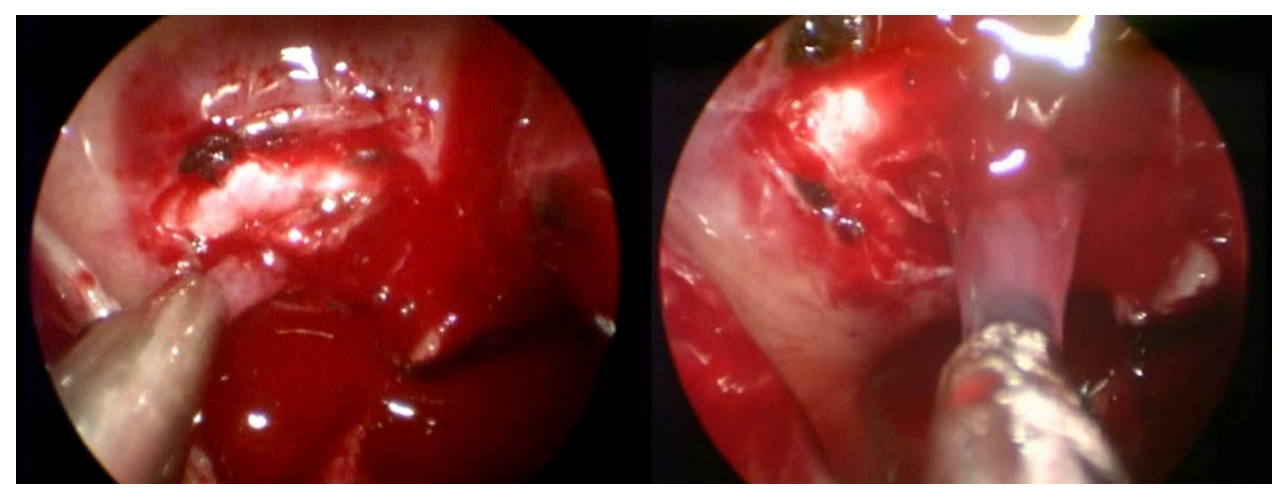

Figure 3. Endonasal endoscopic view. Left side picture showed the rushing out of a solid tumor tissue. Right side picture showed the outflowing of the mucinous contents.

Histology examination of the specimen showed a picture of pituitary tumor tissue with Rathke cleft cyst which composed of cystic space containing myxoid/mucoid material, lined by cuboidal to low columnar epithelium, with underlying collagenous stroma (Figure 4(A)). The remaining pituitary tissue consisted of monomorphic proliferations of cells with uniform round nuclei, delicate stippled chromatin, inconspicuous nucleoli, and moderate quantities of cytoplasm, arranged in solid pattern (Figure 4(B)). Reticulin stain showed loss of normal acinar structure (Figure 4(C)). By immunohistochemistry, the neoplastic cells were positive for FSH (Figure 4(D)), weakly positive for low molecular weight keratin (CAM5.2), and negative for prolactin, ACTH, TSH, $\mathrm{GH}$, and LH immunostains. There are also focal hemorrhage and neutrophil infiltration. Rathke cleft cyst with a coexistent gonadotropin producing adenoma was diagnosed based on the morphology of the tumor cells and the result of immunohistochemical stains.

The patient's postoperative course was uneventful and his vision was much improved after surgery. 1-year post-operative follow-up sellar MRI done in January 2015 showed neither residual nor recurrent sellar lesion (Figure 5). The last endocrinological data checked in August 2014 were within normal limits and now he is not on hormone replacement.

\section{Discussion}

Rathke cleft cysts are benign, epithelial-lined cystic remnants of Rathke pouch and remain asymptomatic in the majority of people [7]. In cases of symptomatic Rathke cleft cyst, the common symptoms are headache, visual disorder, endocrine dysfunction probably caused by the mass effect on the adjacent structures [1] [2] [4] [7] [8]. Magnetic resonance imaging (MRI) is the preferred modality for preoperative evaluation and differentiation of cystic sellar lesions including Rathke cleft cysts, cystic craniopharyngiomas, arachnoid cysts, cystic or hemorrhagic pituitary adenomas, pars intermedia cysts, epidermoid tumors, sellar abscesses and even intrasellar aneu- 


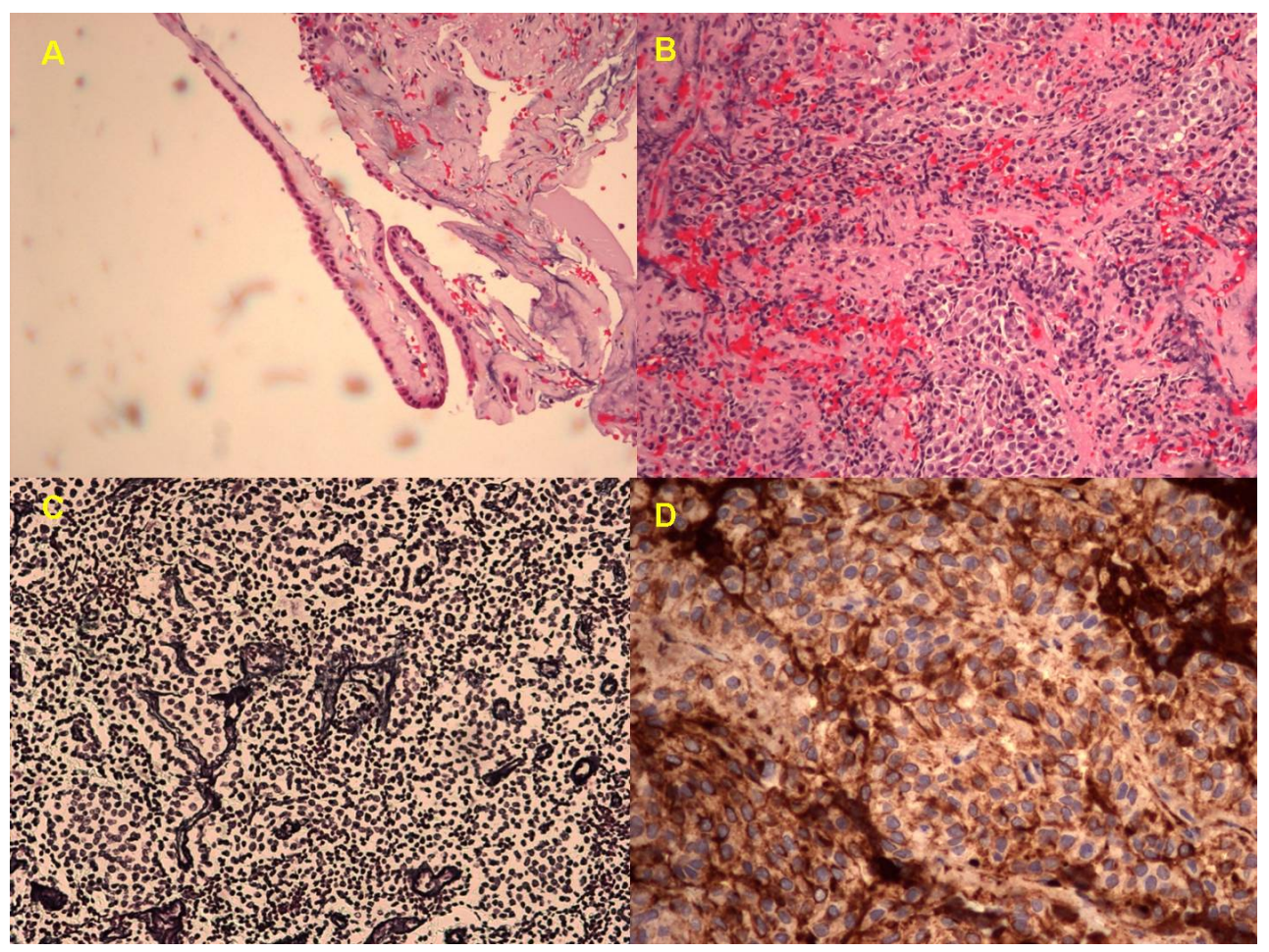

Figure 4. Histology of the cystic mass lesion. (A) Hematoxylin and eosin (H\&E) stain of the cystic component demonstrating cystic space containing myxoid/mucoid material, lined by cuboidal to low columnar epithelium, with underlying collagenous stroma. (B) H\&E stain of the solid component showing monomorphic proliferations of cells with uniform round nuclei, delicate stippled chromatin, inconspicuous nucleoli, and moderate quantities of cytoplasm, arranged in solid pattern. (C) Reticulin stain showing loss of normal acinar structure. (D) Immunostaining of the neoplastic cells revealing positive for FSH.

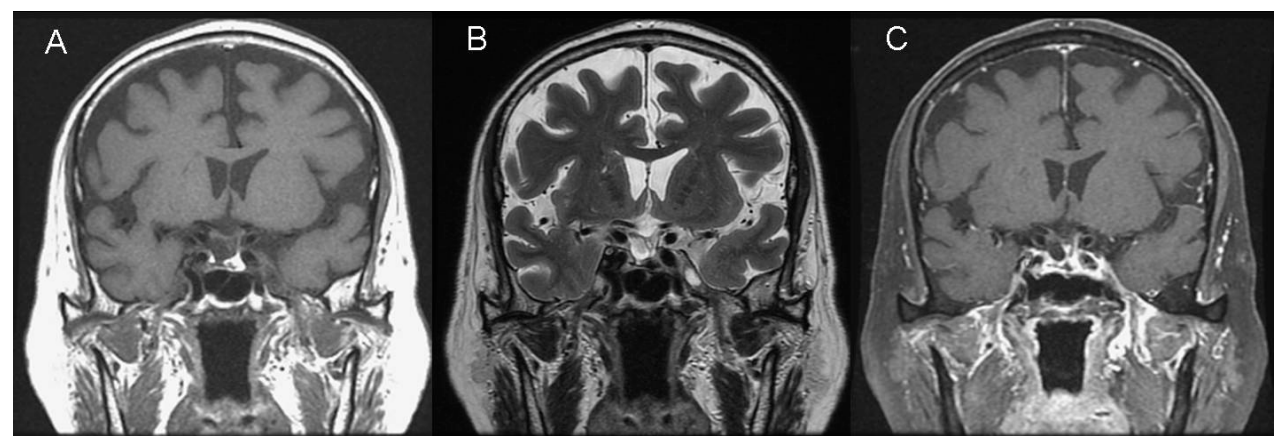

Figure 5. Coronal view of patient's 1-year post-operative follow-up sellar MRI. (A) T1-weighted images; (B) T2-weighted images; (C) T1-weighted with Gadolinium showing neither residual nor recurrent sellar lesion.

rysms [1] [4] [7] [9]. On MRI, Rathke cleft cysts often appear as well-circumscribed, centrally located spherical or ovoid lesions with little or no Gadolinium enhancement of the cystic wall in the sellar region [7]. However, because of the diverse content in the Rathke cleft cysts, they may contain serous or mucoid fluid, mucopolysaccharides, hemosiderin deposits, cellular sediments or particles of cholesterol and protein resulted in variable signal intensity on MRI [1] [2] [7] [9]. A high T1-weighted image intensity has been interpreted to indicate a high content of protein and mucopolysaccharides or hemorrhage. The cystic content of hyper- and iso-intensity on T1-weighted image is usually indicative of mucous with varying viscosity. Rathke cleft cysts with hypointensity on T1-weighted images usually contain CSF-like transparent fluid with low viscosity [2] [9]. 
Rathke cleft cysts have been found incidentally in $11 \%$ - 33\% of post-mortem examinations, and were associated with $1.7 \%-2.1 \%$ of the pituitary adenoma cases [1]-[3] [8]. The relationship between Rathke cleft cyst and pituitary adenoma is still controversial [1] [3]. Associations between these two lesions have been reported to be only occasional and coincidental [3]. Although Rathke cleft cyst and pituitary adenoma have a common embryological ancestry, a pituitary adenoma and a concomitant Rathke cleft cyst rarely occurs. The diagnosis of Rathke cleft cyst with a coexisting pituitary adenoma is difficult before surgery because Rathke cleft cysts show variable size, position and signal intensity on MRI. Nevertheless, the presence of a non-enhancing cyst with a pituitary adenoma suggests the possibility of an accompanying Rathke cleft cyst [2] [9]. Treatment of this unusual coexisting lesion involves surgical resection to decrease mass effect and medical management to normalize hormonal imbalances [2].

\section{Conclusion}

Our patient was diagnosed to have a sellar cystic lesion with suprasellar extension in 2007. This lesion progressed and let him to have significant visual and endocrine dysfunction in 2013. He was successfully treated by endoscopic endonasal transsphenoidal approach with the removal of the sellar lesion and temporary hormone replacement. His bitemporal hemianopia was resolved after surgery and his hormonal imbalance was recovered during the follow-up. The histological examination of the sellar cystic lesion proved to be Rathke cleft cyst with a coexistent gonadotropin producing adenoma which probably is the first reported combination.

\section{References}

[1] Riva, G., Meli, G.A., Chiaramonte, R., et al. (2007) Imaging of Rathke’s Cleft Cysts: Criteria for a Differential Diagnosis. The Neuroradiology Journal, 20, 617-621. http://dx.doi.org/10.1177/197140090702000602

[2] Babu, R., Back, A.G., Komisarow, J.M., et al. (2013) Symptomatic Rathke’s Cleft Cyst with a Co-Existing Pituitary Tumor; Brief Review of the Literature. Asian Journal of Neurosurgery, 8, 183-187. http://dx.doi.org/10.4103/1793-5482.125662

[3] Sumida, M., Arita, K., Migita, K., et al. (2001) Concomitant Pituitary Adenoma and Rathke’s Cleft Cyst. Neuroradiology, 43, 755-759. http://dx.doi.org/10.1007/s002340100559

[4] Kasperbauer, J.L., Orvidas, L.J., Atkinson, J.L.D., et al. (2002) Rathke Cleft Cyst: Diagnostic and Therapeutic Considerations. Laryngoscope, 112, 1836-1839. http://dx.doi.org/10.1097/00005537-200210000-00024

[5] You, C., Qiao, F., Jiang, S. and Xiao, A.Q. (2012) Growth Hormone Secreting Pituitary Adenoma Associated with Rathke's Cleft Cyst. Neurology India, 60, 310-311. http://dx.doi.org/10.4103/0028-3886.98521

[6] Wang, K., Ma, L. and You, C. (2012) Pituitary Adenoma and Concomitant Rathke’s Cleft Cyst: A Case Report and Review of the Literature. Neurology India, 60, 309-310. http://dx.doi.org/10.4103/0028-3886.98520

[7] Zada, G. (2011) Rathke Cleft Cysts: A Review of Clinical and Surgical Management. Neurosurgical Focus, 31, 1-6. http://dx.doi.org/10.3171/2011.5.FOCUS1183

[8] Gessler, F., Coon, V.C., Chin, S.S. and Couldwell, W.T. (2011) Coexisting Rathke Cleft Cyst and Pituitary Adenoma Presenting with Pituitary Apoplexy: Report of Two Cases. Skull Base Reports, 1, 99-104. http://dx.doi.org/10.1055/s-0031-1280737

[9] Noh, S.J., Ahn, J.Y., Lee, K.S. and Kim, S.H. (2007) Pituitary Adenoma and Concomitant Rathke’s Cleft Cyst. Acta Neurochirurgica, 149, 1223-1228. http://dx.doi.org/10.1007/s00701-007-1295-X 